\title{
Presente y futuro de la política económica y comercial de México y del TLCAN ${ }^{+}$
}

Present and future of economic and trade policies of Mexico and NAFTA

\section{Jorge Alfonso Calderón Salazar *}

\begin{tabular}{|c|c|}
\hline Palabras clave & "Profesor Titular de Economía Internacional \\
\hline & Facultad de Economía UNAM. Investigador del \\
\hline & Sistema Nacional de Investigadores. Conacyt. \\
\hline Unidos, integración local & Agradezco a Raúl Carvajal Cortés su colabora- \\
\hline Key words & ción en la elaboración de los cuadros estadísticos. \\
\hline Mesoeconomics, Mexican industry, China and the & + Conferencia impartida en la Facultad de \\
\hline United States, local integration & Economía de la Universidad Nacional Autónoma \\
\hline & de México, Ciudad de México, el 5 de septiembre \\
\hline JEI & de 2017. \\
\hline L60, F15, L16 y 014 & \\
\hline
\end{tabular}

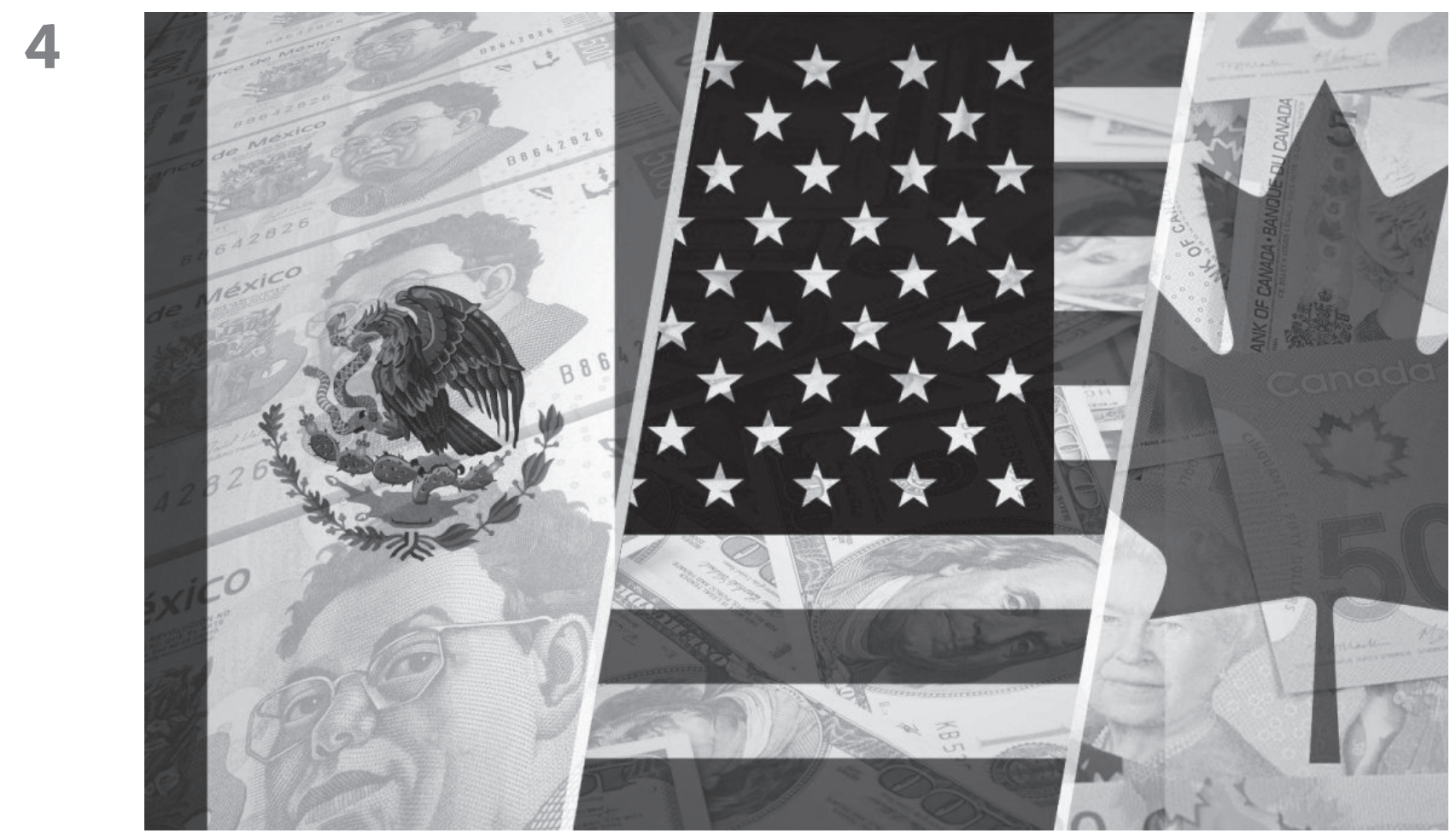

ECONOMÍA INFORMA | 407 | NOVIEMBRE-DICIEMBRE 2017 | 
Jorge Alfonso Calderón Salazar | Presente y futuro de la politica económica

y comercial de México y del TLCAN

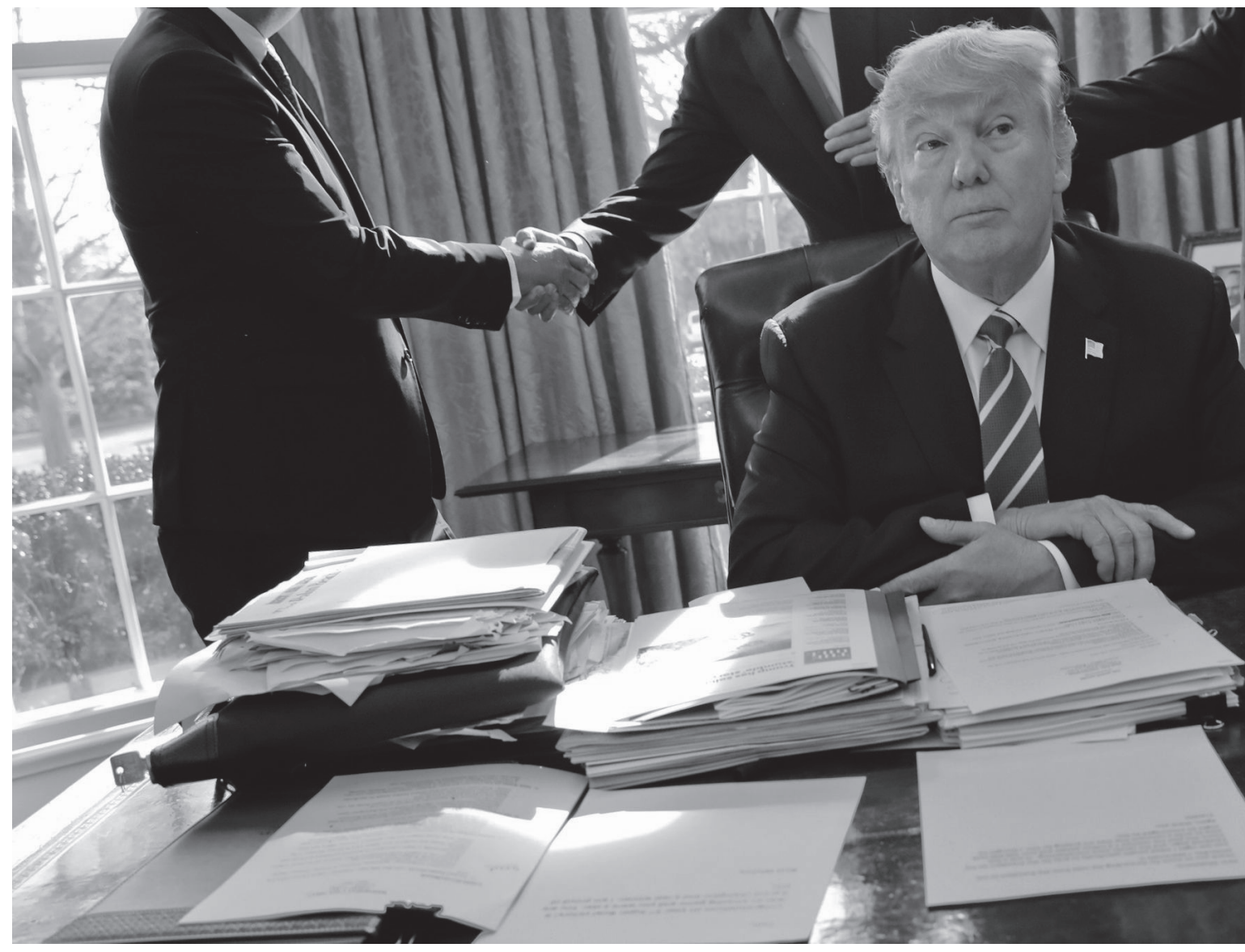

\section{Dinámica de la globalización contemporánea}

En la política internacional hasta los años ochenta existió la confrontación geopolíticomilitar e ideológica entre la Unión Soviética y Estados Unidos, y el activo papel que jugaron los países del Tercer Mundo, así como la lucha de los no Alineados en la búsqueda de una tercera vía entre los países como los nuestros que no ganaban nada en esta confrontación sino el dudoso privilegio de ser el teatro de operaciones de los ajustes de fuerzas entre los polos hegemónicos, o bien ser la recurrente "víctima propiciatoria" causante de los supuestos riesgos a la seguridad global. Este escenario de la segunda posguerra, típico de la llamada "guerra fría”, cambió dramáticamente a principios de los ańos noventa del siglo xx con la desa- parición de la URSS y de las economías centralmente planificadas de Europa Oriental y la emergencia de otros polos en la dinámica económica mundial como Japón, China, India, Corea del Sur, las economías del sudeste asiático y el gradual, pero consistente proceso de expansión y fortalecimiento de la Unión Europea. ${ }^{1}$

El fin del orden bipolar y la tardía e impredecible conformación de uno nuevo, configuran las características de la actual coyuntura. En ella privan el desorden y desajuste de las instituciones internacionales que van perdiendo vigencia sin que lo que se propone para reformarlas o sustituirlas pueda contar

1 Calderón Salazar, Jorge. México y el Nuevo Orden Internacional, Ediciones Praxis, Senado de la República., LVII Legislatura, México, 2000. 


\section{as grandes potencias, espe- cialmente Estados Unidos, los países de la otan, China, Rusia y Japón se arrogan un inaceptable derecho de injerencia violatorio de las normas fundamentales del derecho internacional}

con una destacada participación de los países en vías de desarrollo cuyos intereses nacionales han sido sometidos por la presión de los intereses de las potencias económicas o militares y las multinacionales. Así, por ejemplo, se ratifica el monopolio de las potencias nucleares. Las grandes potencias, especialmente Estados Unidos, los países de la Organización del Tratado del Atlántico Norte (OTAN), -particularmente Francia, Reino Unido y República Federal Alemana-, China, Rusia y Japón se arrogan un inaceptable derecho de injerencia violatorio de las normas fundamentales del derecho internacional.

Se abandona de la agenda internacional temas vitales como son la transformación de la cooperación para el desarrollo entre los Estados en un compromiso jurídico internacional; fincar responsabilidades jurídicas al comportamiento de las transnacionales; reformar el sistema financiero mundial de tal forma que sustente el derecho al desarrollo de los pueblos del mundo y regule las prácticas especulativas y usurarias del gran capital internacional, entre otras demandas importantes.

La mundialización profundiza las desigualdades sociales y regionales, y la vulnerabilidad a las crisis.
Octavio Ianni ${ }^{2}$ al analizar el proceso de globalización, sostiene que:

"Desde que el capitalismo retomó su expansión por el mundo después de la segunda guerra mundial, muchos comenzaron a reconocer que el mundo se estaba volviendo el escenario de un vasto proceso de internacionalización de capital" ${ }^{3}$ Y añade: "esa internacionalización se tornó mas intensa y generalizada, o propiamente mundial, con el fin de la guerra fría, la desagregación del bloque soviético y los cambios de las políticas económicas en las naciones de los regímenes socialistas. A partir de ese momento, las economías de las naciones del ex mundo socialista se transforman en fronteras de negocios , inversiones, asociaciones de capitales, transferencias de tecnologías y otras operaciones que expresan la intensificación y la generalización de los movimientos y de las formas de reproducción del capital a escala mundial". 4

Nuevas formas de confrontación económica y comercial han aparecido en los últimos tiempos. Se fortalecen bloques regionales de comercio y emerge China como nueva potencia económica, lo que, a juicio de algunos autores, configura un escenario internacional caracterizado por la emergencia de una nueva bipolaridad que sustituye la que caracterizó el período de la guerra fría.

Otros autores destacan una creciente multipolaridad caracterizada por la existencia de países y bloques de importancia asimétrica y cambiante en la dinámica económica mundial: Estados Unidos, República Popular China, Unión Europea -particularmente Alemania, Francia, Reino Unido e Italia-, Japón, Rusia,

2 Ianni, Octavio. Teorías de la Globalización, Ed. Siglo xxl, México, 2004.

3 Ibid, p. 31.

4 Ibid. P. 31. 
Jorge Alfonso Calderón Salazar | Presente y futuro de la política económica $y$ comercial de México y del TLCAN

Cuadro 1 Porcentaje de participación de las exportaciones de México a países seleccionados

\begin{tabular}{ccccccccc}
\hline Años & Canadá & $\begin{array}{c}\text { Estados } \\
\text { unidos }\end{array}$ & Brasil & China & $\begin{array}{c}\text { Unión } \\
\text { europea }\end{array}$ & $\begin{array}{c}\text { Corea del } \\
\text { sur }\end{array}$ & Total \\
\hline 2010 & 3.6 & 80 & 1.3 & 1.4 & 4.9 & 0.3 & 100 \\
2011 & 3.1 & 78.5 & 1.4 & 1.7 & 5.5 & 0.4 & 100 \\
2012 & 2.9 & 77.6 & 1.5 & 1.5 & 5.9 & 0.5 & 100 \\
2013 & 2.8 & 78.8 & 1.4 & 1.7 & 5.2 & 0.4 & 100 \\
2014 & 2.7 & 80.2 & 1.2 & 1.5 & 5.1 & 0.5 & 100 \\
2015 & 2.8 & 81.2 & 1 & 1.3 & 4.8 & 0.7 & 100 \\
2016 & 2.8 & 80.9 & 0.8 & 1.4 & 5.2 & 0.7 & 100 \\
2016 a/ & 2.8 & 80.5 & 0.8 & 1.7 & 5.4 & 0.6 & 100 \\
\hline a/ ene-ago & & & & & & & &
\end{tabular}

India, y el resto de los países que integran el G 20, (entre ellos Corea del Sur, Brasil, Sudáfrica, Indonesia, Nigeria, México, Australia, Argentina y otros).

\section{Crítica del proceso de renegociación del TLCAN}

Como resultado de varias décadas de políticas de apertura comercial, ajuste estructural y desregulación de inversión extranjera se aceleró el control de sectores estratégicos por empresas transnacionales. El TLCAN aceleró esta dinámica y generó una crisis agrícola en el sector de granos básicos ya que puso a competir a los campesinos mexicanos con la agricultura más importante de mundo que además se beneficia de subsidios multimillonarios. Por ello no es adecuado como lo proponen algunos voceros empresariales y gubernamentales, defender el TLCAN realmente existente como si fuera la panacea y la salvación de México.

Esta visión crítica del TLCAN y su impacto en la profundización de la dependencia de México respecto a la economía de Estados Unidos la expone el Dr. José Luis León en los siguientes términos:
... (Se) ha exacerbado la bilateralización de las relaciones internacionales de México. Aunque la diversificación de la política exterior ha sido una meta más o menos explícita de todos los gobiernos mexicanos, el peso de la relación con Estados Unidos ha venido en aumento. La agenda bilateral se ha vuelto cada vez más compleja y se ha ampliado hasta incluir temas como el narcotráfico, el manejo de los recursos transfronterizos, los problemas energéticos, la migración, los flujos comerciales, el combate al terrorismo y un largo etcétera. Sin duda alguna, un paso fundamental del proceso de agudización de la dependencia fue la negociación y entrada en vigor del TLCAN en la primera mitad de los noventa. Aunque ... el balance del TLCAN presenta luces y sombras que es necesario analizar in extenso, no se puede soslayar que una de sus consecuencias ha sido aumentar la vulnerabilidad de México ante los ciclos económicos del vecino del norte y disminuir los espacios para disentir de sus propuestas políticas, económicas, y aun de seguridad hemisférica y mundial.

Como contraparte, puede afirmarse que los intentos por diversificar las relaciones exteriores del país han tenido un éxito limitado, ya sea en el plano político o bien en el terreno económico... Ninguna de estas iniciativas, (Tlcuem, otros tratados comerciales, multilateralismo) 
Cuadro 2 Estados UnidosA. Balanza comercial y de servicios (millones de dólares)

\begin{tabular}{lccc}
\hline \multicolumn{1}{c}{ País } & 2014 & 2015 & 2106 \\
\hline China & -314669 & -334022 & -309272 \\
Alemania & -79648 & -77154 & -67007 \\
Japón & -53595 & -55133 & -57083 \\
México & -51322 & -58324 & -63051 \\
India & -30260 & -29568 & -29676 \\
Italia & -27104 & -29743 & -31194 \\
Corea del sur & -14908 & -18591 & -17604 \\
Francia & -13439 & -14569 & -12544 \\
Canadá & -11142 & 4170 & 7731 \\
\hline
\end{tabular}

Fuente: Estadísticas, Departamento de comercio de Estados UnidosA.

sin embargo, consiguió sentar bases sólidas para una diversificación de las relaciones internacionales de México en el largo plazo". ${ }^{5}$

La vulnerabilidad externa de la economía mexicana, el débil crecimiento que ha experimentado durante los últimos 25 años, sus crecientes desequilibrios sociales y regionales, la contracción de su mercado interno y la crisis permanente de inseguridad y falta de legitimidad de sus órganos de gobierno- federal, estatal y municipal-, unido a la elevada concentración de sus exportaciones en Estados Unidos en alrededor del 80\% (cuadro 1) para 2016 y en lo que va de 2017, mientras que y la crónica dependencia de los flujos de inversión extranjera -directa, en cartera y créditos-, provenientes de ese país, origina que el impacto de las previsibles medidas neoproteccionistas del gobierno de Estados Unidos pueda ser significativo para la economía mexicana. Las exportaciones hacia la Unión Europea tienen una participación de 5.4 en 2017 y las destinadas a Canadá representan el 2.8 por ciento para el mismo año.

Con fundamento en el artículo 2202 Estados Unidos propuso renegociar el TLCAN. La renegociación está en marcha desde el mes de agosto. En la práctica se trata de una renegociación de la totalidad de los capítulos del tratado.

El gobierno federal mexicano no ha definido una propuesta integral de renegociación del TLCAN para defender el interés nacional. En algunos discursos el secretario de relaciones exteriores y el secretario de comercio han expuesto breves lineamientos de la política exterior y comercial, pero, salvo que exista de un documento confidencial que se entregó sólo a senadores, la opinión pública de México no dispone de un documento base con las posturas de México en la renegociación.

Además, ha faltado diálogo y consulta con organizaciones civiles, sindicatos, organizaciones campesinas, universidades y pequeños empresarios. Una vez más, como en 1991-1993, los únicos que han sido consultados son las empresas monopólicas que participan en el Consejo Coordinador Empresarial y a los senadores; algunos discursos del secretario de comercio Ildefonso Guajardo de contenido general.

Estados Unidos pretende que México acepte la eliminación de preferencias arancelarias. Además, busca imponer restricciones no aran- 
celarias y aplicar, unilateralmente, más obstáculos a las exportaciones mexicanas, incluidas las agropecuarias. Quiere eliminar el capítulo 19 sobre solución de controversias para subordinar las disputas comerciales a la legislación interna de Estados Unidos y tener la libertad de instrumentar, discrecionalmente, medidas antidumping, restricciones cuantitativas y sanciones comerciales unilaterales. Pretende mayor control y dominio del sector energético y de telecomunicaciones y eliminar las últimas reservas regulatorias aún existentes en estas y otras áreas. Desregular en mayor grado el comercio electrónico y el sector servicios. Y buscará que esto lo apruebe el gobierno mexicano con el argumento de que, si no lo acepta Estados Unidos, en base al artículo 2205 del tratado, se retirará del mismo. Las reiteradas amenazas del presidente Trump en el sentido de que Estados Unidos se retirará unilateralmente del TLCAN, pretenden, precisamente, la capitulación de los negociadores mexicanos ante las pretensiones estadounidenses.

El documento base de los objetivos del gobierno de Estados Unidos en la renegociación del TLCAN fue enviado al Congreso de ese país el 17 de julio del año en curso y se denomina: Resumen de los objetivos para la renegociación del TLCAN". Fue elaborado por la Oficina del Representante de Comercio de Estados Unidos y la Oficina Ejecutiva del Presidente Donald Trump.

En el citado texto se responsabiliza al intercambio comercial de Estados Unidos con los países del TLCAN de que: "los déficit comerciales han explotado" ocultando los astronómicos déficits comerciales de Estados Unidos con China, Alemania y otros países.

En 2014 el déficit de Estados Unidos con respecto a México fue de $51322 \mathrm{mmd}$, para 2015 subió a 58324 mmd y para el 2016 alcanzó los $63051 \mathrm{mmd}$; para el caso de su

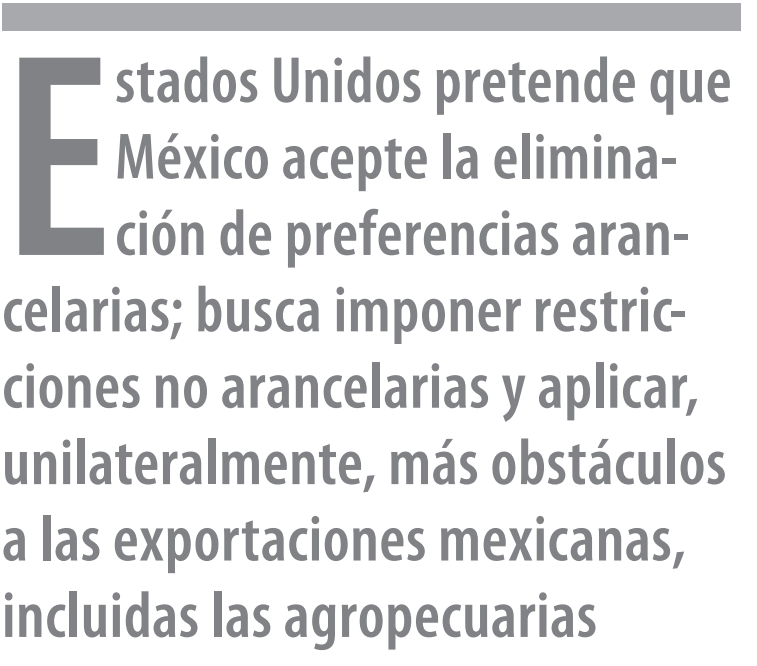

comercio con China en 2014 registraban un déficit comercial eran 314 699, en 2015 se elevó a $334022 \mathrm{mmd}$, y para 2016 se redujo a $309272 \mathrm{mmd}$, ello significa que el saldo negativo de Estados Unidos con China representa aproximadamente cinco veces más del que tiene con México, en promedio para los años de 2014 a 2016. También el " $40 \%$ de lo que importa Estados Unidos de México incluye contenido estadounidense, según cifras del Wilson Center, un centro de investigación con sede en Estados Unidos. En contraste, las exportaciones de China solo tienen $4 \%$ de contenido estadounidense". ${ }^{6} \mathrm{Y}$ las exportaciones, de Estados Unidos hacia China se centran en aeronaves civiles y soya, mientras que las importaciones provenientes de China crecieron principalmente con productos como teléfonos móviles, computadores y equipos de telecomunicaciones.

Con Japón, en 2016, su cuarto socio comercial, la principal economía del mundo tuvo un déficit de 57083 mdd, exportando principalmente, aviones civiles y aeropartes, así como medicinas y equipo médico; mientras

6 Expansión, 26 de enero de 2017 
que sus importaciones se concentraron en autos ligeros, autopartes y accesorios para máquinas industriales.

Ante Alemania, su segundo socio comercial, el país norteamericano registro un déficit comercial en 2016 de 67007 mdd., sus exportaciones, se aglutinaron en autos; aeronaves civiles, motores y aeropartes, también material farmacéutico, mientras que sus principales importaciones fueron de sustancias farmacéuticas, automóviles y autopartes y accesorios.

Con México, su tercer socio comercial, en 2016, Estados Unidos reportó un déficit de 63051 mdd., como se indica en el cuadro 2 , siendo las principales exportaciones de autopartes y accesorios, aparatos eléctricos y accesorios para computadoras. Del lado de importaciones, Estados Unidos compró a México autopartes y accesorios; automóviles, camionetas, autobuses y automóviles para pasajeros.

Además, presenta la desindustrialización de Estados Unidos como resultado exclusivo del TLCAN al decir: "miles de fábricas se han cerrado y millones de estadounidenses se han quedado varados, incapaces de utilizar las habilidades para las que han sido entrenados".

Hasta hoy, las propuestas de Trump sobre los términos de la renegociación han ido acompañadas de reiteradas expresiones xenofóbicas y discriminatorias contra México y los mexicanos, situación a que enrarece el clima social y propicia que, por primera vez en muchos ańos, grupos supremacistas blancos actúen de manera abierta.

Varios estados de la Unión Americana realizan elevadas exportaciones a México: California, Texas y otros. Sus agricultores y ganaderos tienen desde hace años un superávit comercial. Los alimentos provenientes de Estados Unidos has desmantelado los sistemas agrícolas de nuestro país y hoy cubren más del 35\% del consumo alimentario de México.
Es cierto que México tiene un superávit comercial con Estados Unidos, pero ha faltado claridad en la opinión pública y en el gobierno federal del hecho de que la magnitud del déficit comercial mexicano con China, Corea del Sur, Japón y Unión Europea hace que se anule este superávit y el país tiene un persistente déficit comercial global. Y la causa de ello son las cadenas de suministro de insumos, equipos y tecnología proveniente de esos países que se ensamblan en los autos y equipos electrónicos que se exportan a Estados Unidos.

Si las transnacionales instaladas en México desmantelaran algunas sus plantes instaladas en México o redujeran su producción esto tendría generaría impactos negativos, pero no regresarían a Estados Unidos ni se recuperarían los seis millones de empleos manufactureros que han perdido en las últimas décadas. La globalización contemporánea ha generado un proceso de automatización e internacionalización de la producción que es irreversible y el neoproteccionismo tardío de Trump no modificará esta tendencia. En todo caso podría generar una recesión en México, en Estados Unidos y en la economía internacional,-como ya sucedió en el mundo con el auge del proteccionismo en los años 20 y 30 del siglo xx que agudizó la crisis de 1929-. Con sus ataques a México y su pretendida renegociación proteccionista del TLCAN, el flujo de empleos y fábricas de Estados Unidos a China y otros países continuará y se profundizará.

China ya es la segunda economía del mundo, la primera exportadora de manufacturas y como se expuso previamente, tiene un enorme superávit comercial con Estados Unidos que le ha permitido contar con recursos para ser el principal acreedor de Estados Unidos ya que su financiamiento del déficit fiscal y comercial en gran medida depende de China. Si Trump impone sanciones a ese país eso generará mayores 


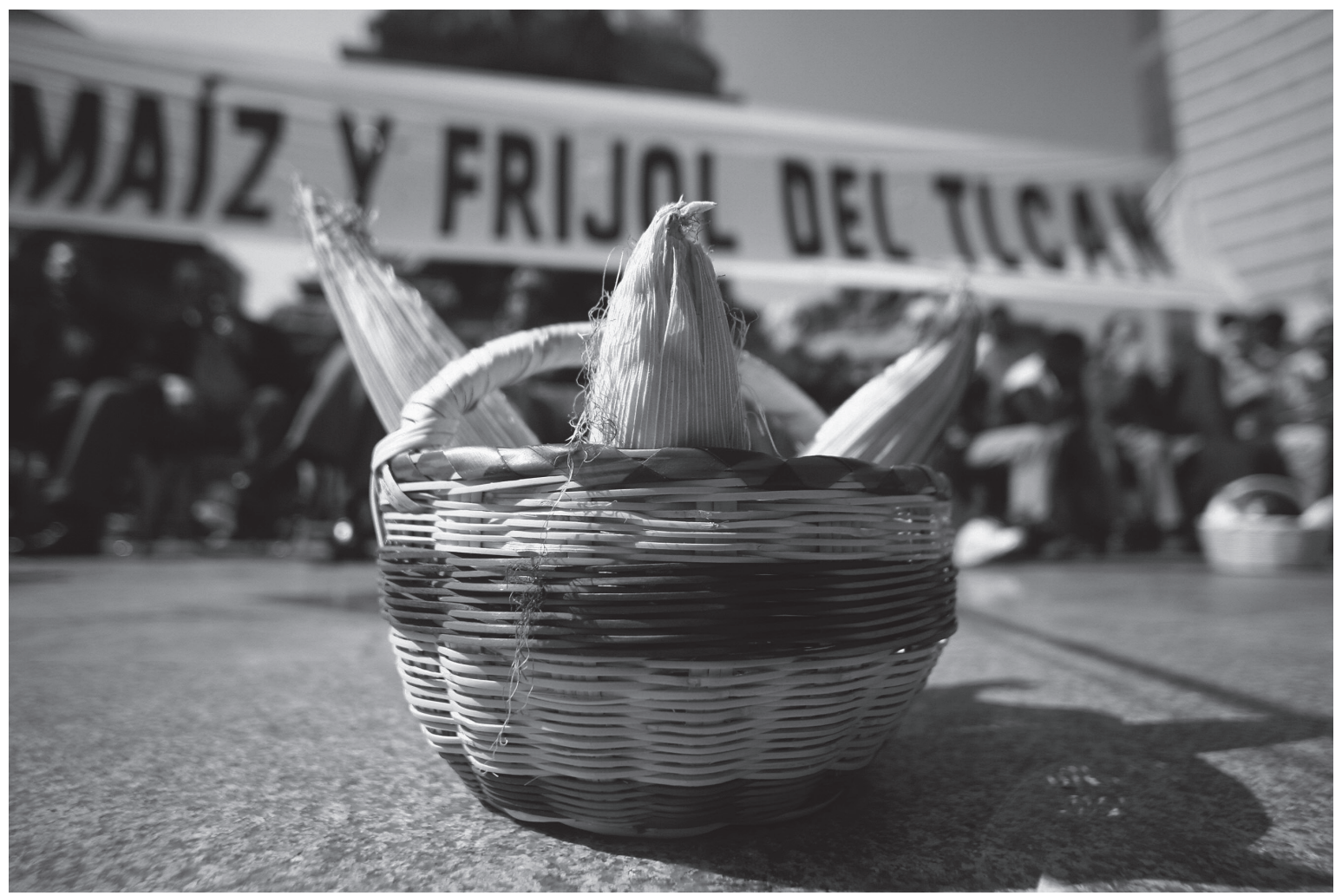

desequilibrios y podría desencadenar un crisis del sistema financiero internacional si Estados Unidos no tuviera suficientes recursos externos para cubrir su déficit fiscal y comercial.

La relación bilateral entre China y Estados Unidos se ha sustentado en elevado consumo interno de Estados Unidos en parte financiado por fuerte endeudamiento público y privado y fuertes exportaciones chinas con el apoyo de un tipo de cambio artificialmente bajo. El gobierno chino prefiere mantener un alto crecimiento -pero inestable- dependiente del comercio internacional, en lugar de la lenta e incierta expansión basada en el mercado interno. Los estadounidenses no tienen voluntad política para equilibrar sus finanzas públicas, por miedo a romper su recuperación económica. ${ }^{7}$

7 www.institutmontaigne.org; consulta mayo 2013. Articulo publicado en 2009: “El G2 y el G 20 , Europa frente a la crisis financiera"
Este acuerdo de interdependencia económica chino-estadunidense genera consecuencias desestabilizadoras para la economía mundial: la volatilidad del mercado de dinero creando volatilidad adicional en los mercados financieros y los elevados flujos internacionales de capital para financiar la deuda soberana de Estados Unidos. ${ }^{8}$

Independientemente de la evolución de las relaciones entre China y Estados Unidos es previsible que Trump y su equipo seguirán utilizando la estrategia que en el pasado han usado demagogos de hacer de un país, una minoría o un grupo social responsable de todos los problemas sociales y económicos. Atacar a México y a los migrantes mexicanos tiene este propósito.

8 Ibid. 
En otra parte del documento "Resumen de los objetivos para la renegociación del TLCAN" establece como objetivo de la renegociación que: "El nuevo TLCAN debe continuar rompiendo las barreras a las exportaciones estadounidenses. Esto incluye la eliminación de las subvenciones injustas, las prácticas que distorsionan el mercado de las empresas estatales y las restricciones onerosas de la propiedad intelectual. El nuevo TLCAN... (abordará) los persistentes desequilibrios comerciales de América en América del Norte. Garantizará que Estados Unidos obtengan un acceso al mercado más abierto... y que nuestro acuerdo comercial con nuestros dos principales mercados de exportación se aplique ...efectivamente". Y ańade, para que no quede duda de que busca Estados Unidos: "un nuevo TLCAN dará a nuestros agricultores, ganaderos, proveedores de servicios y otros negocios nuevas oportunidades para hacer crecer sus exportaciones y recuperar la prosperidad americana".

En comercio de bienes su objetivo es: "mejorar la balanza comercial de Estados Unidos y reducir el déficit comercial con los paises del TLCAN"; (eliminar) las barreras no arancelarias que limitan las exportaciones de Estados Unidos a los países del TLCAN; "Ampliar las oportunidades de mercado competitivas para los productos agrícolas de Estados Unidos en los países del TLCAN". Además pretenden ampliar la utilización de normas sanitarias y fitosanitarias como medio de barreras no arancelarias (estrategia que han aplicado en numerosas ocasiones con las exportaciones mexicanas de aguacate y otros productos agrícolas). Al respecto afirman: "cada pais puede fijar el nivel de protección que considera ser adecuados" y "establecer normas nuevas y aplicables para garantizar que las medidas sanitarias y fitosanitarias".

En reglas de origen su postura es clara: "asegurar que los beneficios del TLCAN se destinen a productos genuinamente fabricados en Estados Unidos y América del Norte (y) ...que las normas de origen incentiven el aprovisionamiento de bienes y materiales de Estados Unidos"

En telecomunicaciones, sector que México, en recientes reformas legislativas ha abierto a la inversión extranjera, Estados Unidos busca: "Promover la oferta competitiva de servicios de telecomunicaciones".

En servicios financieros Estados Unidos pretende: "Ampliar las oportunidades competitivas de los proveedores de servicios financieros de Estados Unidos".

En comercio digital Estados Unidos busca que no se impongan aranceles "a productos digitales (por ejemplo, software, música, video, e-books)".

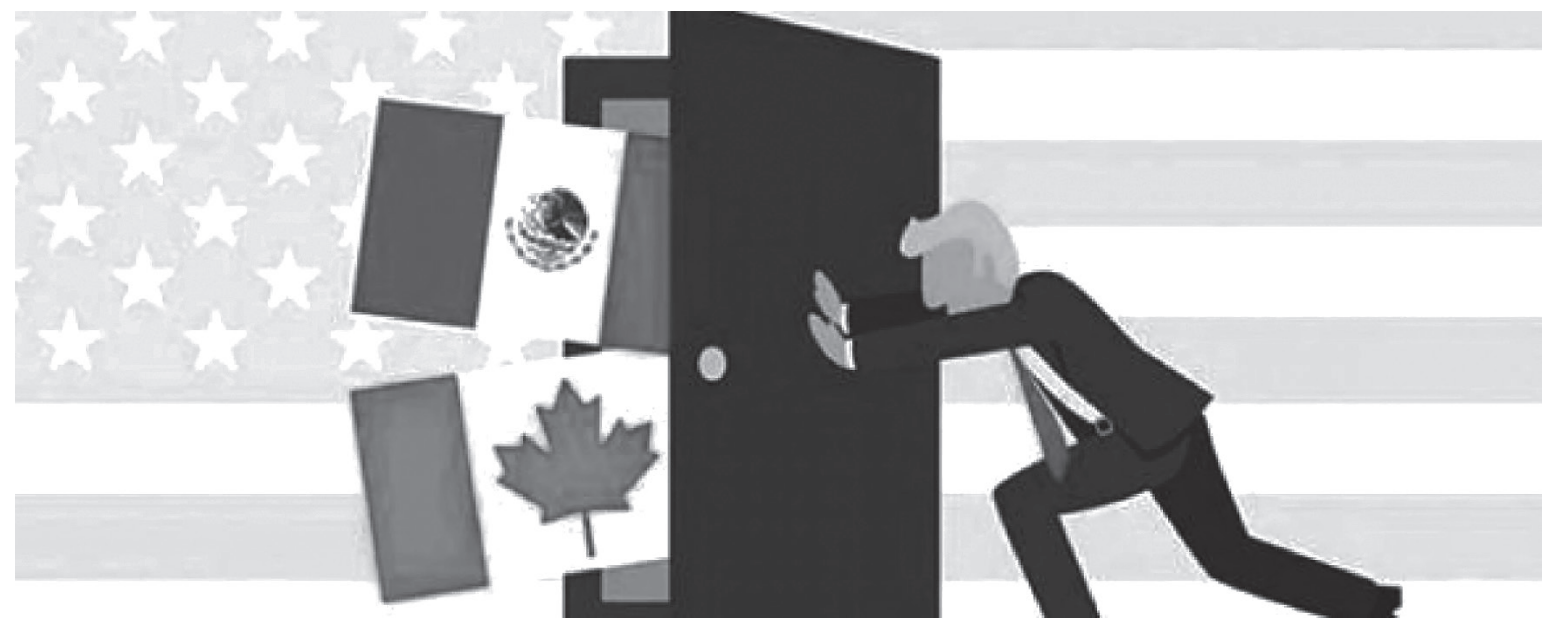


Jorge Alfonso Calderón Salazar | Presente y futuro de la politica económica

y comercial de México y del TLCAN

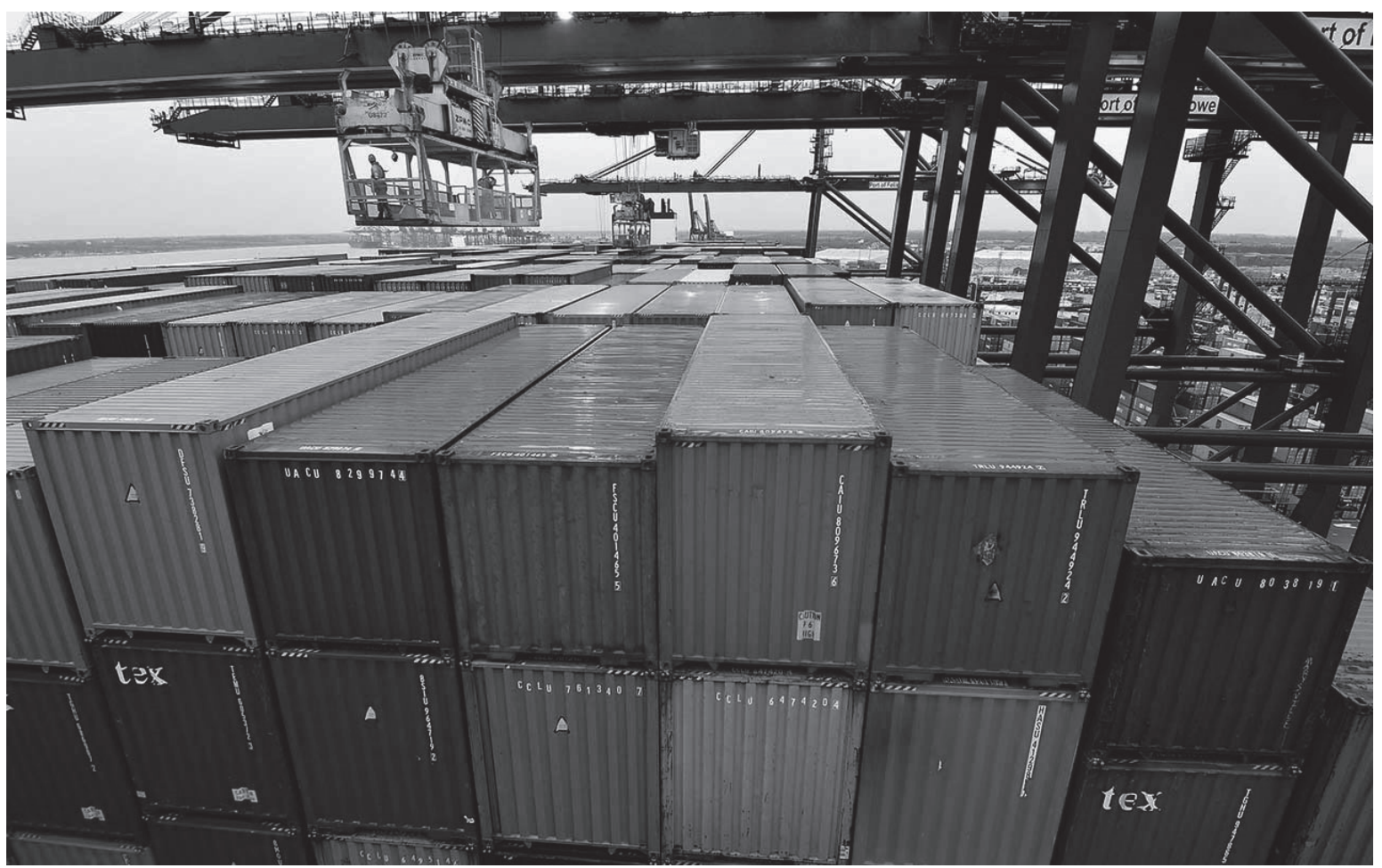

Sin embargo, pese a que en materia de inversión el TLCAN vigente establece una radical desregulación en beneficio de empresas de Estados Unidos y Canadá, impidiendo establecer requisitos de desempeño y códigos de comportamiento, prohibiendo medidas regulatorias y de control de los flujos financieros y de utilidades, dando incluso derecho a que las empresas demanden al gobierno mexicano por políticas económicas o ambientales que afecten sus utilidades, Estados Unidos pretende ampliar los derechos de las empresas de ese país al declarar que buscará: "Establecer reglas que reduzcan o eliminen barreras a la inversión de Estados Unidos en todos los sectores en los países del TLCAN".

En propiedad intelectual, adicional a las normas altamente benéficas para las empresas transnacionales, pues bien, Estados Unidos quiere más y busca: "Garantizar el cumplimiento estricto de los derechos de propiedad intelectual, incluso exigiendo mecanismos civiles, administrativos y penales accesibles, rápidos y eficaces".
Sobre empresas estatales Estados Unidos exige eliminar las últimas barreras y normas regulatorias que aún subsisten en Pemex y CFE a fin de que adquieran más productos de empresas de Estados Unidos al definir que ese país busca: "Asegurar que las empresas estatales otorguen un trato no discriminatorio con respecto a la compra y venta de bienes y servicios". Y, por si esto fuera poco, subordinar las disputas con empresas públicas mexicanas a la jurisdicción de los tribunales de Estados Unidos; al respecto se dice: "Proporcionar jurisdicción a los tribunales sobre las actividades comerciales de las empresas públicas extranjeras".

Una de las propuestas que tiene la mayor relevancia es la eliminación del capítulo 19 de TLCAN sobre solución de controversias para subordinar las disputas comerciales a la legislación interna de Estados Unidos y tener ese país la libertad de instrumentar, discrecionalmente, medidas antidumping, restricciones cuantitativas y sanciones comerciales unilaterales. 
Al respecto Estados Unidos propone, textualmente: "Eliminar el mecanismo de solución de controversias del Capítulo 19". Y se añade, para no dejar lugar a dudas de esta pretensión: preservar la capacidad de Estados Unidos de aplicar rigurosamente sus leyes comerciales, incluidas las leyes antidumping, compensatorias y de salvaguardia" $\mathrm{y}$ : "Eliminar la exclusión de las salvaguardias globales del TLCAN para que no restrinja la capacidad de Estados Unidos de aplicar medidas en investigaciones futuras".

En otro apartado se establece que Estados Unidos busca: "Aumentar las oportunidades de las empresas estadounidenses para vender productos y servicios de Estados Unidos a los paises del TLCAN".

Y defender y ampliar las compras preferenciales en la Unión Americana a empresas de Estados Unidos en sectores como: "Requisitos de "Comprar América" en la asistencia federal a proyectos estatales y locales, servicios de transporte, asistencia alimentaria y apoyo agrícola; adquisiciones clave del Departamento de Defensa y mantener excepciones amplias para la contratación pública con respecto a seguridad nacional" y otras áreas.

En materia de energía, la pretensión es propiciar la completa desregulación y privatización del sector energético y garantizar su seguridad energética. El texto enuncia claramente esto: "Preservar y fortalecer las inversiones, el acceso al mercado y las disciplinas de las empresas estatales que beneficien a la producción y transmisión de energía y apoyen la seguridad e independencia energética de América del Norte, al tiempo que promueven reformas continuas de apertura del mercado de la energía".

Finalmente el objetivo general, asegurar en el nuevo TLCAN la seguridad y objetivos nacionales de Estados Unidos: "Incluir excepciones generales que permitan la protección de legítimos objetivos nacionales de Estados Unidos, incluyendo la protección de la... seguridad esencial, entre otros".

Y por si fuera poco el gobierno de Estados Unidos pretende tener las armas legales para imponer sanciones comerciales a México si, a su juicio, sus exportaciones afectan su balanza de pagos por supuestas ventajas derivadas del tipo de cambio. El texto habla por sí mismo: "asegurar de que los países del TLCAN eviten manipular los tipos de cambio para evitar un ajuste efectivo de la balanza de pagos o para obtener una ventaja competitiva desleal".

Ante las propuestas contenidas en el documento: Resumen de los objetivos para la renegociación del TLCAN" durante las dos rondas de negociación realizadas, la primera en Washington y la segunda a punto de concluir en la Ciudad de México, se percibe que los negociadores de México han aplicado una política de "apaciguamiento". La historia mostró que la estrategia seguida a finales de los años treinta del siglo xx por el primer ministro de Inglaterra, Neville Chamberlain, de ceder ante el expansionismo de la Alemania fascista solo alentó una mayor agresividad de ese régimen y finalmente no evitó en desencadenamiento de la segunda guerra mundial.

\section{Propuestas para la formulación de una nueva política multilateral de relaciones internacionales de México ante el neoproteccionismo de Donald Trump}

México debe definir una agenda propia de renegociación del TLCAN en base a sus intereses nacionales, y no aceptar condiciones regresivas para el país, haciendo énfasis en la renegociación del capítulo agrícola que ha sido profundamente desfavorable para los campesinos mexicanos, definir nuevas reglas de regulación de inversión extranjera, eliminar el trato pri- 


\section{éxico debe definir una agenda propia de rene- gociación del tican en base a sus intereses nacionales, y no aceptar condiciones regresi- vas para el país}

vilegiado a transnacionales de Canadá y Estados Unidos establecidos en el capítulo 11 del TLCAN, proponer un tribunal internacional de solución de disputas comerciales como el que se ha establecido en el Tratado Unión Europea-Canadá y, tomar la iniciativa, pese al clima antiinmigrante, de proponer un acuerdo paralelo al tratado en materia migratoria para promover los derechos de connacionales. Por último, pero no por ello menos importante, renegociar y actualizar con mecanismos de cumplimiento y observancia más eficaces, los acuerdos paralelos en materia ambiental y laboral y el relativo al Banco de Desarrollo de América del Norte.

De no aceptar Estados Unidos estas propuestas y de pretender imponer la administración del presidente Trump un tratado comercial que profundice la subordinación estratégica de la economía mexicana a los intereses de Estados Unidos el gobierno federal mexicano no debe adoptar una política de "apaciguamiento" y mantenerse firme ante las amenazas de Trump . Es mejor salir del TLCAN asumiendo riesgos y costos, resistir y replantear la política mexicana de relaciones económicas internacionales.

México debe rechazar la propuesta que ha expuesto el secretario de comercio de Estados Unidos Wilbur Ross en el sentido de que exis- te la posibilidad de sustituir el TLCAN por un acuerdo bilateral de comercio México- Estados Unidos.

Por otra parte, en inconveniente para el interés nacional de México la precipitación con la que se está renegociando el TLCAN. La primera ronda de negociaciones se realizó en Washington del 16 al 20 de agosto. La segunda se inició el $1^{\circ}$ de septiembre en la Ciudad de México. Y se ha previsto que la siguiente será en Canadá. En suma, se realizarán siete rondas de reuniones cada tres semanas con la intención de tener un nuevo TLCAN a finales de 2017 o principios de 2018. De cumplirse estos períodos se iniciaría un complejo proceso de modificación de leyes de Estados Unidos. Debemos recordar que el TLCAN no fue un tratado comercial ratificado por el senado de ese país. Es un acuerdo vigente con leyes de implementación del mismo que aprueba la Cámara de Representantes. De prolongarse este proceso sería hasta finales de 2018 cuando se podría proponer a votación de ese órgano legislativo; y, para entonces Estados Unidos, estaría en pleno proceso electoral para renovar el congreso. Conclusión: en Estados Unidos pudiera ser votado el referido acuerdo a principios de 2019, después de sus elecciones.

En lo referente a México resulta preocupante que el gobierno federal que concluye sus funciones en noviembre de 2018 propusiera al senado mexicano actual ratificar el nuevo TLCAN antes que el congreso de Estados Unidos; es decir , en el primer semestre de 2018, en pleno proceso electoral de México; y, además, es un órgano legislativo mexicano que será renovado en julio de 2018 ya que en septiembre del mismo año se establece una nueva legislatura con la correlación de fuerzas que surja de la referida elección. Aquí es necesario preguntarse: ¿̨tiene un gobierno y una legislatura a punto de terminar la legitimidad para aprobar un tratado que va a influir de ma- 
nera fundamental en las relaciones comerciales de México en las próximas décadas? ¿No sería mejor, que, independientemente del resultado de la negociación, se dejara la responsabilidad de evaluar el acuerdo renegociado al nuevo gobierno federal que inicia el $1^{\circ}$ de diciembre de 2018 y en su caso permitir que la nueva legislatura de México discuta que es más lo conveniente para México? ¿Cuál es la prisa? Si la nación rechaza un acuerdo lesivo para el interés nacional y opta por salir del TLCAN y normar su relación comercial con Estados Unidos en base a la OMC es mejor que esta decisión la tome el nuevo gobierno y la nueva legislatura.

Es necesario ver más allá del TLCAN y diseñar un escenario post TLCAN. La Organización Mundial de Comercio debe ser la plataforma para relanzar una nueva relación comercial multilateral, replanteando el patrón de relaciones de comercio, servicios, propiedad intelectual, compras de gobierno, inversión y agricultura con diversas regiones y países.

La multipolaridad representa para nuestro país retos y posibilidades para reformular la dinámica de inserción de México en la economía internacional.

Por otra parte, ante el neoproteccionismo chino y su pretensión de centrar el comercio con América Latina y África en productos primarios y dado el elevado superávit comercial de China con México gracias a sus exportaciones manufactureras, -principalmente insumos industriales integrados a las cadenas globales de valor de las exportaciones de ET instaladas en México-, la opción no es un Tratado de Libre Comercio con China; la alternativa es la diversificación de exportaciones: AL, África, Medio Oriente, India, Sudeste Asiático y Oceanía, sin embargo el escepticismo prevalece porque las posibilidades de incremento de exportaciones a Japón, Corea del Sur y Unión
Europea, regiones que predican el libre comercio no se cumplen por las prácticas neoproteccionistas que instrumentas dichos países.

Hay que cambiar la política económica y la política comercial y promover, así sea con décadas de retraso, la diversificación de nuestras exportaciones para depender menos de Estados Unidos. Y fortalecer el mercado interno, y mediante una diversificación promover una nueva política económica centrada en investigación y desarrollo, competitividad, reconversión industrial, subsidios tecnológicos focalizados, aumento de productividad, en suma, generación de ventajas competitivas dinámicas. Diversificación de importaciones de alimentos para reducir la dependencia de Estados Unidos y ampliar las fuentes de abastecimiento además de promover la producción nacional.

De materializarse las amenazas de masiva deportación de connacionales esto afectará en mayor grado a las ciudades fronterizas que viven desde hace varios años una grave crisis social, con creciente desempleo, inseguridad y progresivo cierre de maquiladoras que fueron el motor de sus economías. Más allá de planes, discursos y retórica política el gobierno federal debe instrumentar de inmediato un programa emergente de gasto público en infraestructura urbana, salud, educación y vivienda que permita generar miles de empleos, desde Tijuana hasta Reynosa y Matamoros.

El gobierno federal de México, ante este clima que enrarece la relación binacional y afecta los derechos humanos de nuestros compatriotas, documentados e indocumentados, debe asumir una postura firme y sólida, congruente con los principios constitucionales de política exterior, exigiendo al gobierno de Estados Unidos respeto a México y a los mexicanos, a sus derechos, empleos, remesas, integridad, seguridad, educación y rechazar deportaciones forzadas, violatorias, incluso, de la propia le- 
Jorge Alfonso Calderón Salazar | Presente y futuro de la política económica

$y$ comercial de México y del TLCAN

gislación de ese país. Hacer esto requiere instrumentar una amplia labor de cabildeo en sus medios de comunicación, congreso, gobiernos locales, establecer alianzas con sectores sociales, ONG's y grupos civiles y legisladores demócratas que se oponen a esta retórica excluyente y fortalecer el apoyo de los consulados a nuestras comunidades.

\section{Conclusión}

Las políticas neoproteccionistas de Donald Trump obligan a repensar presente y futuro del TLCAN y de la política económica y comercial. Ante la perspectiva de una renegociación contraria a la soberanía y el interés nacional que profundice la dependencia y subordinación de nuestro país a los intereses hegemóni- cos de Estados Unidos, México debe salir de este tratado comercial y regir sus relaciones comerciales con Estados Unidos y Canadá bajo las normas multilaterales establecidas en la Organización Mundial de Comercio.

Negociar con propuestas, iniciativa, visión y firmeza es lo que se requiere. Con conciencia de que México es una potencia media con una base económica, territorial, demográfica y de recursos que le permite negociar con una política propositiva. Recuperarla la acción diplomática multilateral para reequilibrar la relación bilateral y reconstruir lazos con los países de América Latina y el Caribe. En sumo, no al "apaciguamiento". No aceptar una renegociación del TLCAN que sea lesiva para los intereses nacionales. México es más grande que el TLCAN. ?

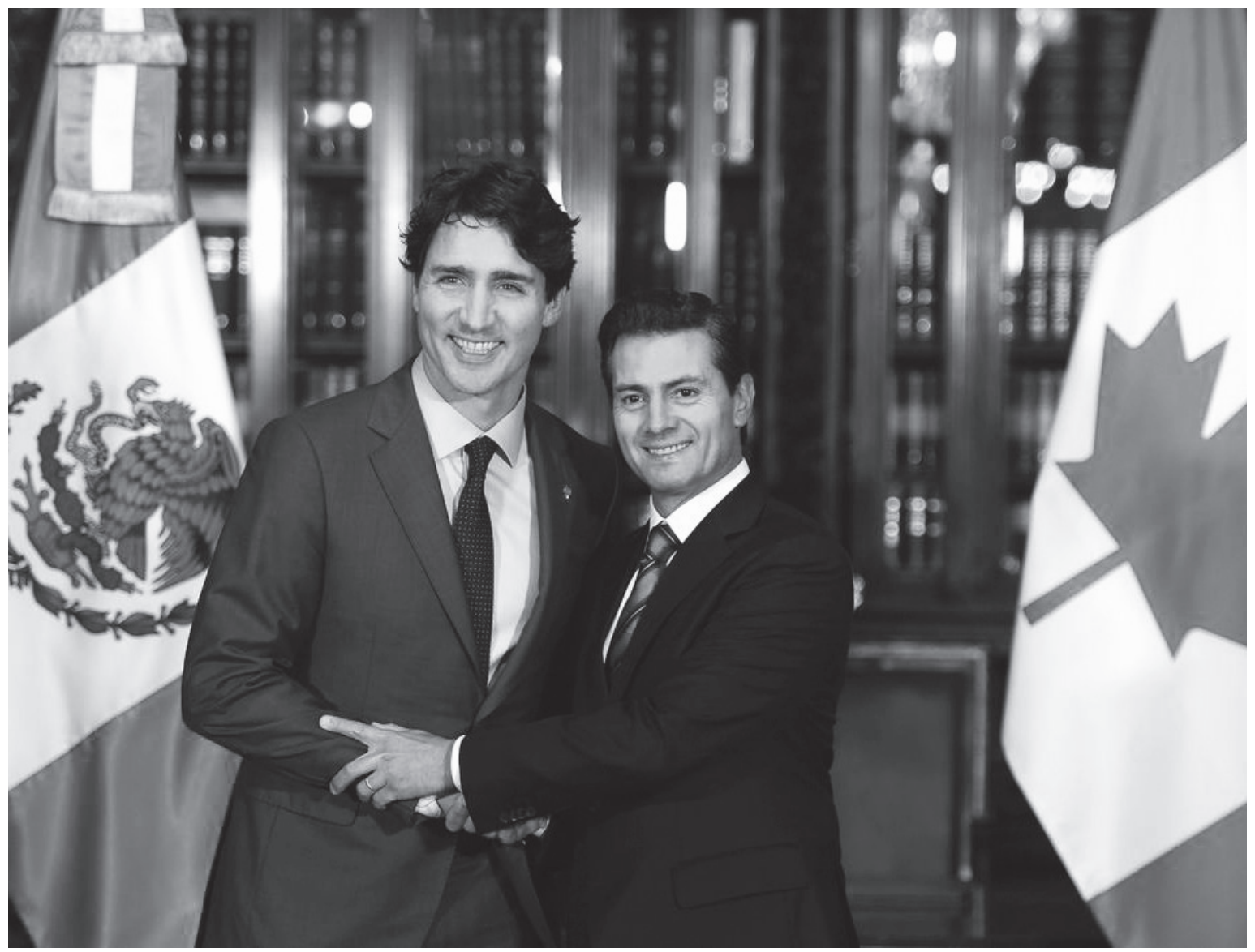

